\title{
Cytogenetic Complete Response
}

National Cancer Institute

\section{Source}

National Cancer Institute. Cytogenetic Complete Response. NCI Thesaurus. Code

C123578.

The disappearance of all signs of cancer, including the absence of a detectable diseaserelated genetic abnormality, as determined by techniques such as karyotyping or FISH, in response to treatment. 